\title{
Prevalence of metabolic syndrome among patients with schizophrenia in Ethiopia
}

\author{
Feyissa Challa ${ }^{1 *}$, Tigist Getahun ${ }^{1}$, Meron Sileshi ${ }^{1}$, Zeleke Geto ${ }^{2}$, Teshome S. Kelkile ${ }^{3}$, Sintayehu Gurmessa ${ }^{4}$, \\ Girmay Medhin ${ }^{5}$, Miraf Mesfin ${ }^{4}$, Melkam Alemayehu ${ }^{4}$, Tigist Shumet ${ }^{1}$, Anwar Mulugeta ${ }^{6}$, Desalegn Bekele ${ }^{4}$,

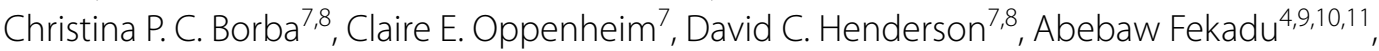 \\ Anna Carobene ${ }^{12}$ and Solomon Teferra ${ }^{4}$
}

\begin{abstract}
Background: Globally, the prevalence of metabolic syndrome (MetS) is higher among patients with schizophrenia than the general population, and this leads to higher morbidity and mortality in this population. The aim of this study was to investigate the MetS prevalence among patients with schizophrenia in Ethiopia.

Methods: We conducted a cross-sectional analysis of baseline data of 200 patients with schizophrenia recruited from Amanuel Mental Specialized Hospital, Addis Ababa, Ethiopia. Lipid profile and blood glucose levels were measured using Roche Cobas 6000 clinical chemistry analyzer. The prevalence of MetS was assessed based on National Cholesterol Education Program Adult Treatment Panel III criteria. Patients' demographic information, clinical and laboratory data, lifestyle habits, particularly smoking and Khat chewing, were evaluated vis-à-vis MetS.

Results: The overall prevalence of MetS in patients with schizophrenia was 21.5\% (17.1\% male, 29.6\% female) where Low HDL-cholesterol value was the most common metabolic disorders components in both males and females subgroups. In the multivariate analysis, the positive and negative symptoms score (PANSS, AOR $=1.03,95 \% \mathrm{Cl} 1.001-$ 1.054) was associated factors with MetS.

Conclusion: In Ethiopia, patients with schizophrenia were found to have higher prevalence of MetS than the general population. Physicians/health care providers should routinely screen patients with schizophrenia for MetS and initiate timely management of those who develop the syndrome to reduce the health cost from caring for NCDs, improve the patients' quality of life, and prevent premature mortality.
\end{abstract}

Keywords: Metabolic syndrome, Prevalence, Schizophrenia, Ethiopia

\section{Introduction}

Schizophrenia is one of severe mental disorder that affects $1 \%$ of the total population globally and is accompanied by serious functional impairments [1]. Patients with schizophrenia have approximately $20 \%$ reduced life expectancy compared to the general population [2].

\footnotetext{
*Correspondence: Feyissawaka@gmail.com

${ }^{1}$ National References Laboratory for Clinical Chemistry, Ethiopian Public Health Institute, Gulelle Arbegnoch Street (the former Pasteur Institute): Gulele Sub City, Addis Ababa, Ethiopia

Full list of author information is available at the end of the article
}

Schizophrenia is in fact a life-threatening disease associated with mortality rates that are two to three times higher than those expected/observed in the general population [3], and in a study in Ethiopia based on a 5 years follow up, up to six fold increase in overall mortality has been reported [4]. Suicide is one of the factors for death in patients with schizophrenia [5], but the high mortality is also related to natural causes such as respiratory diseases [6], cancer [7], and cardiovascular diseases (CVDs) [8]. The high prevalence of unhealthy dietary habits, sedentary lifestyle, obesity, and smoking habits among 
patients suffering from schizophrenia have been referred as significant contributing factors for a higher than normal risk of developing CVDs, constellation of clinical findings that identify the metabolic syndrome [9].

Metabolic syndrome (MetS), known also as" Insulin Resistance Syndrome" or "Syndrome X", comprises several clinical aspects attributable to a higher than normal risk of developing diabetes mellitus or CVDs which is characterized by high fasting blood glucose and high triglycerides concentrations, low level of high density lipoprotein (HDL), and high waist circumference [10].

Several criteria are used to define the MetS, like the definition from the National cholesterol Education Program Adult Treatment Panel (commonly referred as ATP III or NCEP criteria), the Adopted definition (NCEP ATP III A), from the World Health Organization (WHO), from the American Diabetes Association (ADA's), and also from the Japan Society for the study of Obesity (JASSO) [11]. The two definitions most commonly used are the ATP III A criteria, proposed by American Heart Associations (AHA), and the WHO definition, that, differently from ATP III, includes also the albuminuria and abnormal glucose regulation [12].

Globally, the prevalence of MetS among patients with schizophrenia is twice higher than the general population [13]. In Ethiopia, the prevalence of MetS among the general population has been recently determined in a large sample size, but evidence about the prevalence of MetS among patients with schizophrenia in low income countries is scarce. Few studies were conducted in Ethiopia, particularly in capital city (Addis Ababa), southern and western part of Ethiopia, to assess the prevalence of MetS among patients with psychiatric illness [14-16]. The aim of this study was to investigate the prevalence of MetS among patients with schizophrenia in Ethiopia. The findings from this study will inform clinicians in Ethiopia to institute appropriate interventions to prevent the development of MetS. It will also add to the body of knowledge on MetS among schizophrenia patients from LMICs.

\section{Methods}

\section{Study participants}

We conducted a cross-sectional analysis of a baseline data of two hundred outpatients study participants recruited at the Amanuel Mental Specialized Hospital, Addis Ababa, Ethiopia from January, 2015 and November, 2016. Diagnoses were made by psychiatrists according to Diagnostic and Statistical Manual of Mental Disorders Fourth edition (DSM-IV) [17] as part of folate clinical trial, (Clinicaltrials.gov identifier: NCT01724476), a 4month trial of Folate plus Vitamin B12 in Ethiopia) [18]. Patients who had positive and negative symptoms score (PANSS) of 60 or higher were included in the study. The study was reviewed and approved by both Addis Ababa University, College of Health Science, Institutional Review Board (Protocol \#040/12/SPH) and Massachusetts General Hospital Review Board (Protocol \#2011-P-002667). All study participants provided written informed consent.

\section{Assessment}

At the baseline visit general information were collected from outpatients with schizophrenia by filling in an enrollment questionnaire by trained psychiatric nurse under four main headings:

1. Patient's demographic information: age, sex, ethnicity, marital status, and occupational status.

2. Patient's clinical data: height, weight, waist circumference (measured) and body mass index (BMI). Blood pressure was measured twice by standard mercury sphygmomanometers on the right hand after the study participants seated for $5 \mathrm{~min}$ and the average of the two readings was used for the data analysis. Both pharmacological treatment and illness duration data were collected from medical history.

3. Patient's lifestyle habits: smoking and Khat chewing status was assessed (Yes/No response). Khat is an evergreen shrub (Catha Edulis Forsk) which has amphetamine like stimulant property and a common habit in East Africa [19].

4. Patient's clinical laboratory data: total cholesterol, HDL- cholesterol, triglycerides, and fasting blood glucose concentrations were measured, as described below.

\section{Laboratory analysis}

Whole blood (4-5 ml) was collected from study participants by experienced laboratory technologist after overnight fasting for $8 \mathrm{~h}$ and allowed to clot for $30 \mathrm{~min}$ before centrifugation at $4500 \mathrm{rpm}$ for $5 \mathrm{~min}$. Serum samples were separated and total cholesterol, HDL cholesterol, triglycerides, and glucose were measured the same day using Roche Cobas 6000 analyzer (Roche Diagnostics $\mathrm{GmbH}$, Mannheim, Germany). The measurements were performed at the National Reference Laboratory for Clinical Chemistry of Ethiopia Public Health Institute (EPHI). This laboratory undergoes an external quality assessment scheme and is accredited by the Ethiopia National Accreditation Office (ENAO). Diagnosis of MetS was established using the NCEP/ATPIII A criteria (Table 1).

\section{Statistical analysis}

The descriptive statistics used for the categorical data were frequencies and percentages, while for the continuous data mean, median, standard deviations (SD), 
Table 1 Criteria for metabolic syndrome classification according to the NCEP/ATPIII A

\begin{tabular}{ll}
\hline & NCEP ATP III A \\
\hline Definition & Any three of the following 5 features \\
Waist Circumference $(\mathrm{cm})$ & Male $\geq 102$, Female $\geq 88$ \\
Blood Pressure $(\mathrm{mm} \mathrm{Hg})$ & Systolic $\geq 130$, or Diastolic $\geq 85$ \\
Triglyceride $(\mathrm{mg} / \mathrm{dl})$ & $\geq 150$ \\
Fasting blood glucose $(\mathrm{mg} / \mathrm{dl})$ & $\geq 100$ \\
HDL Cholesterol $(\mathrm{mg} / \mathrm{dl})$ & $\mathrm{M}<40, \mathrm{~F}<50$ \\
\hline
\end{tabular}

Abbreviations: NCEP ATP III A National Cholesterol Education Programs Adult Treatment Panel III

and interquartile range (IQR) were applied. Differences between categorical and continuous data were evaluated using Pearson Chi-square test or Fisher's exact test and logistic regression, respectively. In multivariate analysis model, after removing parameters used in the diagnosis of MetS, variables with $p$-value lower than 0.05 were included in the analysis. The presence of MetS was used as dependent categorical variable in both univariate analysis and multiple logistic regressions. A $p$-value $<0.05$ was considered significant. Statistical analysis was performed using SPSS Version 22.00 (SPSS Inc. Chicago, IL, USA). The figures were performed using python 3.7.

\section{Results}

\section{Demographic and clinical characteristics}

Socio-demographic characteristics of participants stratified according to the gender are presented in Table 2 . A total of 200 (129 males, 71 females) patients with schizophrenia were recruited in this study, with mean age $38.4 \pm 9.8$ years. One-third of patients with schizophrenia had high BMI $\left(\geq 25 \mathrm{Kg} / \mathrm{m}^{2}\right)$. The mean duration of the illness in the patients was $14 \pm 9$ years, and $66 \%$

Table 2 Demographic and clinical characteristics of study subjects

\begin{tabular}{|c|c|c|c|}
\hline & Total & Male & Female \\
\hline Number of subjects, n (\%) & 200 & 129(64.5) & $71(35.5)$ \\
\hline Age (in years) mean $\pm S D$ & $38.4 \pm 9.8$ & $38.4 \pm 10.1$ & $38.4 \pm 9.4$ \\
\hline Waist circumference in $\mathrm{cm}$ mean $\pm \mathrm{SD}$ & $89.3 \pm 9.7$ & $88.4 \pm 8.7$ & $91 \pm 11$ \\
\hline $\mathrm{BMI}\left(\mathrm{Kg} / \mathrm{m}^{2}\right) \geq 25 \mathrm{n}(\%)$ & $73(36.5)$ & $32(24.8)$ & $41(57.7)$ \\
\hline \multicolumn{4}{|l|}{ Ethnicity n (\%) } \\
\hline Amhara & $82(41.0)$ & 48(37.2) & $34(47.9)$ \\
\hline Oromo & $45(22.5)$ & $30(23.3)$ & 15(21.1) \\
\hline Tigray & $8(4.0)$ & $5(3.9)$ & $3(4.2)$ \\
\hline Gurage & $42(21.0)$ & 28(21.7) & 14(19.7) \\
\hline others & 23(11.5) & 18(14.0) & $5(7.0)$ \\
\hline Systolic Blood pressure $(\mathrm{mm} \mathrm{Hg})$ mean $\pm \mathrm{SD}$ & $120 \pm 18$ & $121 \pm 17$ & $118 \pm 21$ \\
\hline Diastolic Blood Pressure $(\mathrm{mm} \mathrm{Hg})$ mean $\pm \mathrm{SD}$ & $78.4 \pm 11.5$ & $78.7 \pm 11.7$ & $78.0 \pm 11.1$ \\
\hline \multicolumn{4}{|l|}{ Pharmacological treatment n (\%) } \\
\hline FGAs & $132(66.3)$ & $88(68.8)$ & $44(62.0)$ \\
\hline SGAs & $67(33.7)$ & $40(31.2)$ & $27(38.0)$ \\
\hline Lives with parental family n (\%) & 160(80.0) & 112(86.8) & $48(67.6)$ \\
\hline PANSS Score mean \pm SD & $83.6 \pm 15.4$ & $84.0 \pm 15.4$ & $82.9 \pm 15.6$ \\
\hline Smokers n (\%) & $42(21.4)$ & $41(32.5)$ & $1(1.4)$ \\
\hline \multicolumn{4}{|l|}{ Khat chewing Status n (\%) } \\
\hline Yes & $16(8.2)$ & $16(12.7)$ & $0(0)$ \\
\hline No & 180(91.8) & $110(87.3)$ & $70(100)$ \\
\hline Occupational Status, working n (\%) & $44(22.0)$ & $29(22.5)$ & $15(21.1)$ \\
\hline Duration of illness (Years), mean $\pm S D$ & $14 \pm 9$ & $15 \pm 9$ & $14 \pm 9$ \\
\hline Marital Status, Married n (\%) & $28(14.0)$ & 15(11.6) & 13(18.3) \\
\hline Total Cholesterol (mg/dl), median (IQR) & 183(216-157) & $176(211-154)$ & 198(221-174) \\
\hline Triglycerides (mg/dl), median (IQR) & 118(164-83) & $123(179-87)$ & 103(149-77) \\
\hline HDL-Cholesterol (mg/dl), median (IQR) & $45(54-38)$ & 43(49-36) & $50(60-44)$ \\
\hline $\mathrm{FBG}(\mathrm{mg} / \mathrm{dl})$, median (IQR) & $91(100-86)$ & $91(98-86)$ & $91(103-86)$ \\
\hline
\end{tabular}

Abbreviations: COR Crude odds ratios, SD standard deviation, BMI Body mass index, WC Waist Circumference, BP blood pressure, PANSS Positive and Negative Syndrome Scale, FGAs first generation antipsychotics, SGAs second generation antipsychotics, HDL high-density lipoprotein, FBG Fasting blood glucose, IQR interquartile range 
of the patients were using the first-generation antipsychotic (FGA) medication while only $34 \%$ the second generation of antipsychotic (SGA). Approximately $21 \%$ were smokers, $8 \%$ gave a history of chewing Khat, $78 \%$ were not working, $86 \%$ were single during the study period, and over two-thirds lived with parental family.

\section{Prevalence of metabolic syndrome and its components}

Low HDL-cholesterol value was the most common metabolic disorders component in both males and females subgroup as shown in the Fig. 1. High waist circumference was present in the female group with a high percentage, but not common in the male subgroup, while high triglycerides level was the least metabolic disorder component in both females and males subgroup (Fig. 1, Table 3).
The overall prevalence of MetS among patients with schizophrenia, according to NCEP ATP III A criteria was 43(21.5\%) (22 males and 21 females), while, 157 patients (78.5\%), presented 2 or less MetS criteria (Table 4).

\section{Associated factors with metabolic syndrome}

To determine the associated factors to the MetS, patients were divided in with $43(21.5 \%)$ and without MetS 157(78.5\%) subgroups. Age, BMI, marital status (married/single), occupational status (working/not working), pharmacological treatment (FGAs/SGAs), Khat Chewing use (Yes/No), and living arrangement (with parental/ marital family or other), were found as factors not associated to the MetS. Gender, PANSS score, and smoking habit were found associated with MetS in univariate analysis. In multivariate analysis only PANSS score were
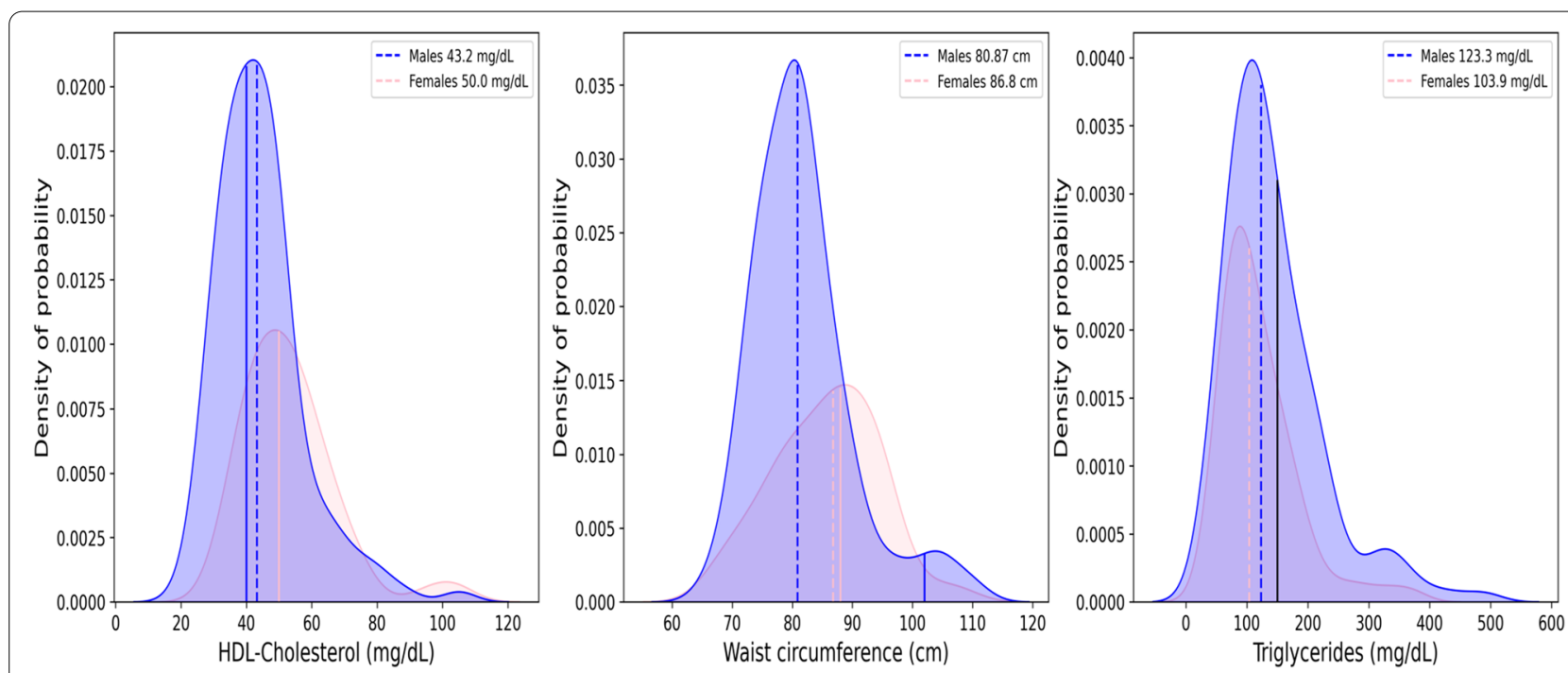

Fig. 1 Distributions of HDL-Cholesterol (panel A), waist circumference (panel B), and triglycerides (panel $\mathbf{C}$ ) values for males and females (blue and pink area, respectively). Dotted lines represent the median values and the continuous line the limits defined as criteria for the metabolic syndrome (MetS) classification differentiated for sex, if necessary, as reported in Table 1. HDL Cholesterol median value for female subgroup is overlapped to the criteria defined for the MetS $(50 \mathrm{mg} / \mathrm{dL})$

Table 3 Prevalence of metabolic abnormalities in patients with schizophrenia n (\%)

\begin{tabular}{llllll}
\hline NECP ATP III & Total & Male & Female & $\begin{array}{l}\text { OR female to male } \\
(\mathbf{9 5 \%} \text { Cl) }\end{array}$ & $P$ value \\
\hline WC $(M>102 \mathrm{~cm} ; \mathrm{F}>88 \mathrm{~cm})$ & $50(25.0)$ & $9(7.0)$ & $41(57.7)$ & $18.2(8.0-41.6)$ & $<0.001$ \\
Triglycerides $(\geq 150 \mathrm{mg} / \mathrm{dl})$ & $61(30.7)$ & $44(34.4)$ & $17(23.9)$ & $0.6(0.3-1.2)$ & 0.126 \\
BP $(\geq 130 / 85 \mathrm{mmHg})$ & $74(37.0)$ & $50(38.8)$ & $24(33.8)$ & $0.8(0.4-1.5)$ & 0.487 \\
HDL Cholesterol $(\mathrm{M}<40 \mathrm{mg} / \mathrm{dl} ;$ & $88(44.4)$ & $54(42.5)$ & $34(47.9)$ & $1.24(0.7-2.2)$ & 0.466 \\
F $<50 \mathrm{mg} / \mathrm{dl})$ & & & & $1.7(0.8-3.3)$ & 0.114 \\
FPG $(\geq 100 \mathrm{mg} / \mathrm{dl})$ & $49(24.9)$ & $27(21.3)$ & $22(31.4)$ & & \\
\hline
\end{tabular}

Abbreviations: NCEP ATP III National Cholesterol Education Programs Adult Treatment Panel III, WC Waist Circumference, BP blood pressure, HDL high-density lipoprotein, $M$ males, $F$ females, FBG Fasting blood glucose 
Table 4 Prevalence of metabolic abnormalities according to the NCEP ATP III A criteria among patients with schizophrenia in Ethiopia

\begin{tabular}{llll}
\hline Number of MetS criteria & Total $\mathbf{n}(\%)$ & \multicolumn{2}{l}{ Gender } \\
\cline { 3 - 4 } & & Male $\mathbf{n}(\%)$ & Female $\mathbf{n}(\%)$ \\
\hline 0 & $45(22.5)$ & $35(27.1)$ & $10(14.1)$ \\
1 & $57(28.5)$ & $36(27.9)$ & $21(29.6)$ \\
2 & $55(27.5)$ & $36(27.9)$ & $19(26.8)$ \\
3 & $25(12.5))$ & $16(12.4)$ & $9(12.7)$ \\
4 & $12(6.0)$ & $4(3.1)$ & $8(11.3)$ \\
5 & $6(3.0)$ & $2(1.6)$ & $4(5.6)$ \\
MetS $\geq 3$ criteria & $43(21.5)$ & $22(17.1)$ & $21(29.6)$ \\
\hline
\end{tabular}

Abbreviations: MetS metabolic syndrome found associated factor with MetS in patients suffering from schizophrenia (Table 5).

In Figs. 2 and 3 are shown ages and BMIs distributions among people with and without MetS.

\section{Discussion}

In this study we reported the prevalence and associated factors for metabolic syndrome among patients with schizophrenia which is the first study to compare the findings to the national population prevalence of MetS. The Ethiopian community based survey, conducted from April to June 2015 , in a population of 10,260 adults people, quoted a prevalence of metabolic syndrome of $4.8 \%$ (8.6\% in females and $1.8 \%$ in males respectively) [20]. In the current study, we investigated the prevalence of MetS among two hundreds patients suffering from schizophrenia in Ethiopia. The overall prevalence of MetS among these patients was $22 \%$ according to the ATP III A

Table 5 Univariate and multivariate analysis to evaluate associated factors to the metabolic syndrome in patients suffering from schizophrenia in Ethiopia $(n=200)$

\begin{tabular}{|c|c|c|c|c|c|c|}
\hline \multirow{2}{*}{$\begin{array}{l}\text { Variable } \\
\text { Number of patients (\%) }\end{array}$} & \multicolumn{2}{|c|}{ Metabolic Syndrome } & \multirow[t]{2}{*}{$\operatorname{COR}(95 \% \mathrm{Cl})$} & \multirow[t]{2}{*}{$P=$ value } & \multirow[t]{2}{*}{ AOR(95\%Cl) } & \multirow[t]{2}{*}{$P=$ value } \\
\hline & Yes, 43(21.5)) & No, $157(78.5)$ & & & & \\
\hline \multicolumn{7}{|l|}{ Age (in Years) n (\%) } \\
\hline$<30$ & $3(7.0)$ & $30(19.1)$ & 1 & & & \\
\hline$\geq 30$ & 40(93.0) & 127(80.9) & $0.32(0.09-1.1)$ & 0.70 & & \\
\hline \multicolumn{7}{|l|}{ Sex $n(\%)$} \\
\hline Male & $22(51.2)$ & 107(68.2) & 1 & & 1 & \\
\hline Female & $21(48.8)$ & $50(31.8)$ & $2.04(1.03-4.06)$ & 0.041 & $0.63(0.30-1.34)$ & 0.231 \\
\hline \multicolumn{7}{|l|}{ Marital status n (\%) } \\
\hline Married & $9(20.9)$ & 19(12.1) & 1 & & & \\
\hline Single & $34(79.1)$ & 138(87.9) & $1.92(0.8-4.6)$ & 0.144 & & \\
\hline \multicolumn{7}{|l|}{ Occupation status $\mathrm{n}(\%)$} \\
\hline Working & $11(25.6)$ & $33(21.0)$ & 1 & & & \\
\hline Not working & $32(74.4)$ & 124(79.0) & $1.29(0.59-2.83)$ & 0.523 & & \\
\hline PANSS Score mean \pm SD & $78 \pm 13$ & $85 \pm 16$ & $1.03(1.01-1.06)$ & 0.012 & $1.03(1.001-1.054$ & 0.046 \\
\hline Duration of illness (in Years) mean $\pm S D$ & $16 \pm 9$ & $14 \pm 9$ & $0.98(0.94-1.02)$ & 0.288 & & \\
\hline \multicolumn{7}{|l|}{ Current treatment $\mathrm{n}(\%)$} \\
\hline FGAs & $29(67.4)$ & 103(66.0) & 1 & & & \\
\hline SGAs & 14(32.6) & $53(34.0)$ & $0.94(0.46-1.93)$ & 0.862 & & \\
\hline \multicolumn{7}{|l|}{ Smoking status $\mathrm{n}(\%)$} \\
\hline No & $37(92.5)$ & 117(75.0) & 1 & & & \\
\hline Yes & $3(7.5)$ & $39(25.0)$ & $4.1(1.2-14.1)$ & 0.024 & $3.2(0.88-11.7$ & 0.077 \\
\hline \multicolumn{7}{|l|}{ Khat Chewing status $n(\%)$} \\
\hline No & $37(92.5)$ & 143(91.7) & 1 & & & \\
\hline Yes & $3(7.5)$ & $13(8.3)$ & $1.12(0.30-4.14)$ & 0.864 & & \\
\hline \multicolumn{7}{|l|}{ Living arrangement $\mathrm{n}(\%)$} \\
\hline Lives with parental family & $30(69.8)$ & 130(82.8) & 1 & & & \\
\hline Lives with marital family & $8(18.6)$ & 17(10.8) & $0.49(0.19-1.24)$ & 0.133 & & \\
\hline Lives with other relatives/lives alone & $5(11.6)$ & $10(6.4)$ & $0.46(0.15-1.50)$ & 0.185 & & \\
\hline
\end{tabular}




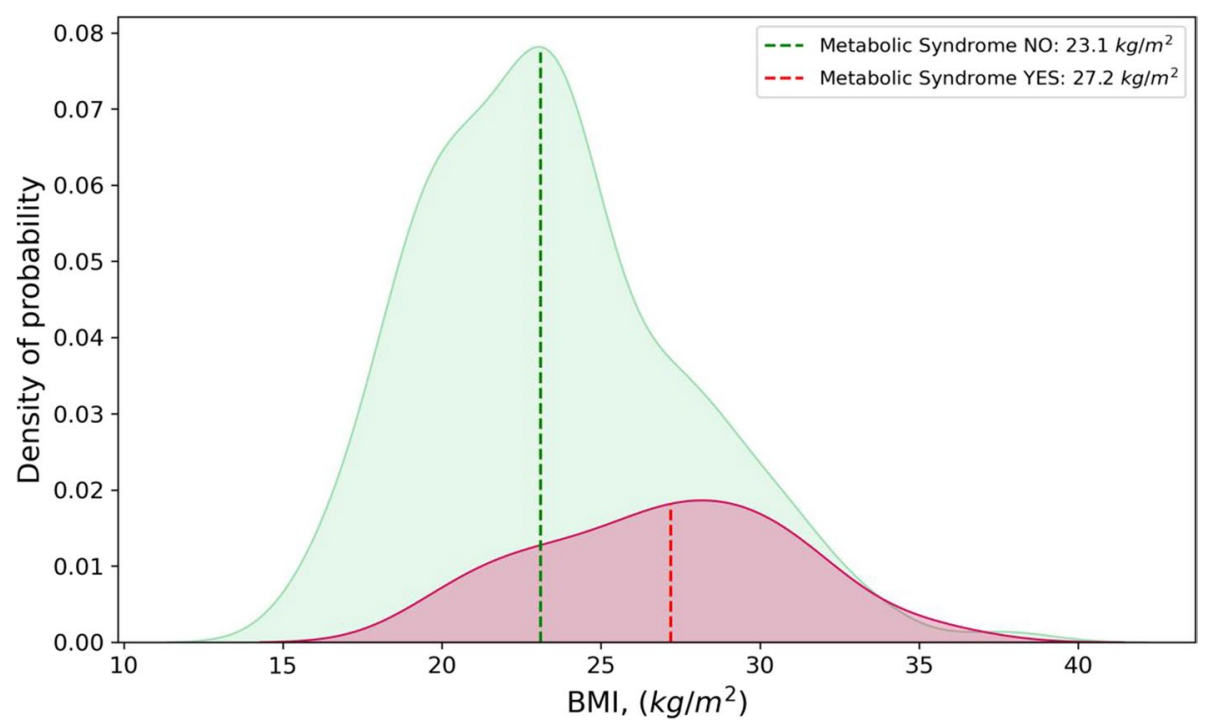

Fig. 2 Distributions of Body Mass Index (BMI) values, for patients with and without diagnosis of metabolic syndrome (MetS) (red and green area respectively). Dotted lines represent the median values of the subgroup-

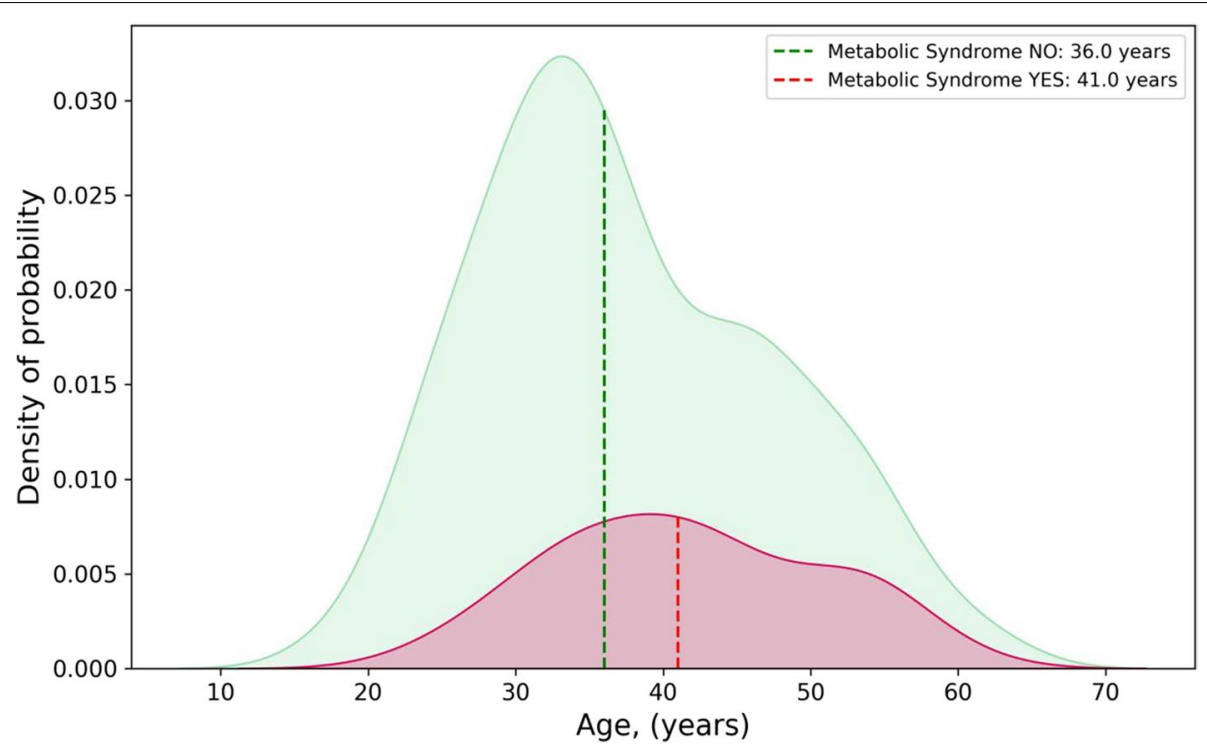

Fig. 3 Distributions of ages, for patients with and without diagnosis of metabolic syndrome (MetS) (red and green area respectively). Dotted lines represent the median values of the subgroup

criteria with higher proportion among females compared to males (29.6 and $17.1 \%$ respectively).

The etiology of the MetS among patients with schizophrenia is multifactorial and this includes psychotropic drugs such as second-generation antipsychotics, immune-metabolic dysregulations, and lifestyle risk factors (e.g. physical inactivity, smoking, excessive alcohol intake, poor sleep, and unhealthy nutritional patterns) [9]. The immune dysregulations include increased levels of inflammatory markers such as $\mathrm{C}$ - reactive protein (CRP), interlukin-6 (IL-6), tumour necrosis factor alpha (TNF alpha), and other cytokines indicating insulin and leptin resistance, obesity, inflammation, and higher rates of metabolic syndrome [21]. Recent study indicated that plasma apelin level higher among schizophrenia patients which may be related to severity of mental illness which impact on MetS [22]. 
A recent systematic review and meta-analysis by Vancampfort and et al. [23] indicated that the pooled prevalence of MetS among patients with severe mental illness ranged between 25 and $50 \%$, and the finding of our current study is comparable with the range reported globally. Other evidences among patients with schizophrenia indicated prevalence of MetS of $42 \%$ (51.6\% of women, 36\% men) in a study conducted in USA [24], a prevalence of 42.6 and $48.5 \%$ for men of women respectively in a Canadian study [25], 27.5\% in Japan [26], 43.6\% in Palestine [27], 46.7\% in Malaysia [28], 40\% in Turkey [29], and 40\% in India [30].

Studies conducted in different part of the African continent indicated that the prevalence of MetS is comparable with the global data. For instance, in a study carried out in South Africa on 278 subjects with severe mental illness, the estimated prevalence of MetS was 23.2\% [31]; whereas, in the middle belt of Ghana $14.1 \%$ [32]. The report from Kenya was slightly higher at $28.6 \%$ [33]. Three studies conducted in the central, south, and western part of the Ethiopia among patients with psychiatric illness, diagnosed with schizophrenia, major depressive disorder, bipolar disorder and others, reported prevalence of MetS ranged from 18 to 25\% [14-16]. Our finding is comparable to those reported by previous studies even though our study include only patients diagnosed with schizophrenia.

Similar to our study, higher prevalence of MetS was reported from different studies among females compared to male patients with schizophrenia $[24,25]$, and this was consistent with the MetS finding from the Ethiopian general population survey [20]. One important reason for high MetS among females might be due to use of hormonal contraceptives [34].

The present study found increasing PANSS score associated with MetS. The relationship between increasing PANSS score and MetS has been already reported in patients with schizophrenia [35, 36] and this could be explained by certain habits such as sedentary lifestyle and /or dietary habits as factors contributing to obesity.

There is inconsistent reports on the relation between the different generations of antipsychotic medications and MetS among patients with schizophrenia [36-39]. In this study, we did not find significant difference in the development of MetS between first generation and second generation antipsychotic medications (FGAs or SGAs). Even though there is inconsistent report between MetS and antipsychotic medication, increasing evidence indicates that the disease itself is an independent risk factor to develop MetS, as demonstrated by the presence of higher rates of MetS in antipsychotic naïve patients [40].

The current approach for the diagnostic criteria for MetS, the cut-off point of waist circumference has been debated. Most published literature widely used criterion in ATPIII defined $102 \mathrm{~cm}$ in men and $88 \mathrm{~cm}$ in women as the cut-off points to diagnose MetS, mainly developed based on data from western population. In addition the IDF criterion (2005) suggest the cut-off values of waist circumferences to be $90 \mathrm{~cm}$ in men and $80 \mathrm{~cm}$ in women [12]. In our study, as reported in Table 3, only 9 males (7\%) presented a value of waist circumference higher than the cut off, while the prevalence of waist circumference abnormality in females is $>50 \%$ (Table 3 , Fig. 1). A cross-sectional community-based study in nine Ethiopian regions, including more than 5.000 recruited participants, reported a percentage of obesity among the population of $2.2 \%(\mathrm{BMI}>30)$ [41] while in US the obesity is a common disease regarding more than $40 \%$ of the population [42]. Africa which have great cultural, linguistic, and historic diversity the cut-off point of waist circumferences depends on western population which might not to be appropriate for Africa population, at least for Ethiopia.

Even though the prevalence of metabolic syndrome among patients suffering from schizophrenia is high, the rate of screening for this syndrome among these patients is still low, especially in low and middle-income countries [43]. A recent meta-analysis of prospective cohort studies by Wu et al. [44], showed that individuals with MetS had had $46 \%$ increased risk of mortality when compared with individuals without MetS. The higher prevalence of metabolic syndrome among patients with schizophrenia compared with the general population has several clinical consequences for this vulnerable group such as the development of chronic diseases and subsequent premature mortality. The consequence is grave in LIMICs where quality health services are low or inaccessible.

\section{Limitations}

The current study has some limitations. First, we conducted a cross-sectional analysis of baseline data study which referred only about a single point in study. Second, we applied only one criterion (ATP III A criteria) to estimate the prevalence of MetS among patients with schizophrenia and not use control to make comparison. Third, potential factors for the development of MetS such as genetic variations, and lifestyle such as physical exercise and diet were not included.

\section{Conclusion}

The prevalence of Mets among patients with schizophrenia in Ethiopia is much higher than the general population. The current finding highlights the need for screening of MetS components in patients with schizophrenia, particularly those who have high BMI and older patients. 


\section{Acknowledgements}

We gratefully acknowledge the financial support of the Stanley Medical Research Institute (SMRI), which supported the Folate trial and the Ethiopian Public Health Institute, National References laboratory for Clinical Chemistry for supporting the laboratory analysis by providing laboratory facility.

\section{Authors' contributions}

$F C, T S, A F$, and $S T$ were the principal investigators of this component the study. FC, TS, AM, AF, DB, AC, and ST took the leading role from conception, design, and supervising the data collection process up to the final analysis and preparation of the manuscript. CP, CE, and DC participated in reviewing the method part and provided critical comments. DB, AC, ST, AF, FC and AC contributed to the writing of the manuscript. GM and $A C$ participated in data analysis. MM, MA, TS, AM, and SG coordinated the project and were responsible for the data acquisitions. ZG, MS and TG contributed to the methodology and laboratory analysis. All authors read and approved the final manuscript.

\section{Funding}

This study was funded by The Stanley Medical Research Institute (SMRI).

\section{Availability of data and materials}

The datasets used and analyzed during the current study are available from the first Corresponding author Feyissa Challa on reasonable request.

\section{Declarations}

\section{Ethics approval and consent to participate}

Ethical Clearance was obtained from the Institutional Review Board (IRB) of Addis Ababa University, College of Health Sciences (Protocol \#040/12/ $\mathrm{SPH}$ ). Written informed consent was obtained from each participants after a detailed explanation of the objectives of the study, risk, and benefits. All methods were carried out in accordance with 1964 Declaration of Helsinki.

\section{Consent for publication}

Not applicable.

\section{Competing interests}

Authors have declared that no competing interests exist.

\section{Author details}

${ }^{1}$ National References Laboratory for Clinical Chemistry, Ethiopian Public Health Institute, Gulelle Arbegnoch Street (the former Pasteur Institute): Gulele Sub City, Addis Ababa, Ethiopia. ${ }^{2}$ Department of Biomedical Science, College of Medicine and Health Science, Wollo University, Dessie, Wollo, Ethiopia. ${ }^{3}$ Horizon Health Network, Fredericton, NB, Canada. ${ }^{4}$ Department of Psychiatry, School of Medicine, College of Health Sciences, Addis Ababa University, Addis Ababa, Ethiopia. ${ }^{5}$ Aklilu Lemma Institute of Pathobiology Addis Ababa University, Addis Ababa, Ethiopia. ${ }^{6}$ Australian Centre for Precision Health, University of South Australia, Adelaide, Australia. ${ }^{7}$ Boston University School of Medicine, Boston, MA, USA. ${ }^{8}$ Boston Medical Center, Boston, MA, USA. ${ }^{9}$ Centre for Innovative Drug Development and Therapeutic Trials for Africa (CDT-Africa), College of Health Sciences, Addis Ababa University, Addis Ababa, Ethiopia

${ }^{10} \mathrm{Global}$ Health \& Infection Department, Brighton and Sussex Medical School, Brighton, UK. ${ }^{11}$ King's College London, Centre for Affective Disorders, Department of Psychological Medicine, Institute of Psychiatry, Psychology and Neuroscience, London, UK. ${ }^{12}$ Laboratory Medicine, IRCCS San Raffaele Scientific Institute, Milan, Italy.

Received: 15 September 2021 Accepted: 29 November 2021 Published online: 11 December 2021

\section{References}

1. McGrath J, Saha S, Chant D, Welham J. Schizophrenia: a concise overview of incidence, prevalence, and mortality. Epidemiol Rev. 2008;30:67-76 https://doi.org/10.1093/epirev/mxn001.
2. Laursen TM, Wahlbeck K, Hällgren J, Westman J, Ösby U, Alinaghizadeh H, et al. Life expectancy and death by diseases of the circulatory system in patients with bipolar disorder or schizophrenia in the Nordic countries. PLoS One. 2013;8(6):e67133 https://doi.org/10.1371/journal.pone.0067133.

3. Auquier $\mathrm{P}$, Lançon C, Rouillon F, Lader M. Mortality in schizophrenia. Pharmacoepidemiol Drug Saf. 2007;16(12):1308-12 https://doi.org/10.1002/ pds.1496.

4. Teferra S, Shibre T, Fekadu A, Medhin G, Wakwoya A, Alem A, et al. Fiveyear mortality in a cohort of people with schizophrenia in Ethiopia. BMC Psychiatry. 2011;11:165 https://doi.org/10.1186/1471-244X-11-165.

5. Hor K, Taylor M. Suicide and schizophrenia: a systematic review of rates and risk factors. J Psychopharmacol. 2010;24(4 Suppl):81-90 https://doi. org/10.1177/1359786810385490.

6. Bouza C, López-Cuadrado T, Amate JM. Physical disease in schizophrenia: a population-based analysis in Spain. BMC Public Health. 2010;10:745 https://doi.org/10.1186/1471-2458-10-745

7. Grinshpoon A, Barchana M, Ponizovsky A, Lipshitz I, Nahon D, Tal O, et al. Cancer in schizophrenia: is the risk higher or lower? Schizophr Res. 2005;73(2-3):333-41 https://doi.org/10.1016/j.schres.2004.06.016.

8. Correll CU, Solmi M, Veronese N, Bortolato B, Rosson S, Santonastaso P, et al. Prevalence, incidence and mortality from cardiovascular disease in patients with pooled and specific severe mental illness: a large-scale meta-analysis of 3,211,768 patients and 113,383,368 controls. World Psychiatry. 2017;16:163-80 https://doi.org/10.1002/wps.20420.

9. Citrome L. Metabolic syndrome and cardiovascular disease. J Psychopharmacol. 2005;19(6 Suppl):84-93.

10. Grundy SM, Cleeman II, Daniels SR, Donato KA, Eckel RH, Franklin BA, et al. Diagnosis and management of the metabolic syndrome: an American Heart Association/National Heart, Lung, and Blood Institute scientific statement. Circulation. 2005;112(17):2735-52 https://doi.org/10.1161/ CIRCULATIONAHA.105.169404.

11. National Cholesterol Education Program (NCEP) Expert Panel on Detection, Evaluation, and Treatment of High Blood Cholesterol in Adults (Adult Treatment Panel III). Third report of the National Cholesterol Education Program (NCEP) expert panel on detection, evaluation, and treatment of high blood cholesterol in adults (adult treatment panel III) final report. Circulation. 2002;106(25):3143-421.

12. Expert Panel on Detection, Evaluation, and Treatment of High Blood Cholesterol in Adults. Executive summary of the third report of the National Cholesterol Education Program (NCEP) expert panel on detection, evaluation, and treatment of high blood cholesterol in adults (adult treatment panel III). JAMA. 2001;285:2486-97.

13. De Hert M, Schreurs V, Vancampfort D, Van Winkel R. Metabolic syndrome in people with schizophrenia: a review. World Psychiatry. 2009;8:15-22 https://doi.org/10.1002/j.2051-5545.2009.tb00199.x.

14. Amogne G, Alemu T, Tadesse T, Mullu A. Magnitude of metabolic syndrome and its predictors among patients on second-generation antipsychotic drugs at six psychiatry clinics and mental hospitals, in Addis Ababa, Ethiopia, 2019; Multicenter cross-sectional study. Diabetes Metab Syndr. 2021;15:102187 https://doi.org/10.1016/j.dsx.2021.102187.

15. Teshome T, Kassa DH, Hirigo AT. Prevalence and associated factors of metabolic syndrome among patients with severe mental illness at Hawassa, Southern-Ethiopia. DMSO. 2020;13:569-79 https://doi.org/10. 2147/DMSO.S235379

16. Asaye S, Bekele S, Tolessa D, Cheneke W. Metabolic syndrome and associated factors among psychiatric patients in Jimma University specialized hospital, South West Ethiopia. Diabetes Metab Syndr. 2018;12(5):753-60 https://doi.org/10.1016/j.dsx.2018.04.037.

17. Association. AP. Diagnostic and Statistical Manual of Mental Disorders, 5th Edition (DSM-5). Diagnostic Stat Man Ment Disord. 2013. Available from http://repository.poltekkes-kaltim.ac.id.

18. Borba CPC, Fekadu A, Teferra S, Bekele D, Shibre T, Oppenheim CE, et al. A placebo-controlled trial of Folate with B12 in patients with schizophrenia with residual symptoms in Ethiopia using a sequential parallel comparison design. J Adv Med Med Res. 2014;4(23):4090-104 https://doi.org/10. 9734/BJMMR/2014/10473.

19. Reda AA, Moges A, Biadgilign S, Wondmagegn BY. Prevalence and determinants of Khat (Catha edulis) chewing among high school students in eastern Ethiopia: a cross-sectional study. PLoS One. 2012;7(3):e33946 https://doi.org/10.1371/journal.pone.0033946. 
20. Gebreyes YF, Goshu DY, Geletew TK, Argefa TG, Zemedu TG, Lemu KA, et al. Prevalence of high bloodpressure, hyperglycemia, dyslipidemia, metabolic syndrome and their determinants in Ethiopia: evidences from the national NCDs STEPS survey, 2015. PLoS One. 2018;13(5):1-18 https:// doi.org/10.1371/journal.pone.0194819.

21. Könner AC, Brüning JC. Selective insulin and leptin resistance in metabolic disorders. Cell Metab. 2012;16(2):144-52 https://doi.org/10.1016/j. cmet.2012.07.004.

22. Sahpolat M, Ari M, Kokacya MH. Plasma Apelin, Visfatin and Resistin levels in patients with first episode psychosis and chronic schizophrenia. Clin Psychopharmacol Neurosci. 2020;18(1):109-15 https://doi.org/10.9758/ cpn.2020.18.1.109.

23. Vancampfort D, Stubbs B, Mitchell AJ, De Hert M, Wampers M, Ward PB, et al. Risk of metabolic syndrome and its components in people with schizophrenia and related psychotic disorders, bipolar disorder and major depressive disorder: a systematic review and meta-analysis. World Psychiatry. 2015;14(3):339-47 https://doi.org/10.1002/wps.20252.

24. McEvoy JP, Meyer JM, Goff DC, Nasrallah HA, Davis SM, Sullivan L, et al. Prevalence of the metabolic syndrome in patients with schizophrenia: baseline results from the clinical antipsychotic trials of intervention effectiveness (CATIE) schizophrenia trial and comparison with national estimates from NHANES III. Schizophr Res. 2005;80(1):19-32 https://doi. org/10.1016/j.schres.2005.07.014.

25. Cohn T, Prud'homme D, Streiner D, Kameh H, Remington G. Characterizing coronary heart disease risk in chronic schizophrenia: high prevalence of the metabolic syndrome. Can J Psychiatr. 2004;49(1 1):753-60 https:// doi.org/10.1177/070674370404901106.

26. Sugawara N, Yasui-Furukori N, Sato Y, Kishida I, Yamashita H, Saito M, et al. Comparison of prevalence of metabolic syndrome in hospital and community-based Japanese patients with schizophrenia. Ann General Psychiatry. 2011;10(1):21 https://doi.org/10.1186/1744-859X-10-21.

27. Sweileh WM, Zyoud SH, Dalal SA, Ibwini S, Sawalha AF, Ali I. Prevalence of metabolic syndrome among patients with schizophrenia in Palestine. BMC Psychiatry. 2012;12:235 https://doi.org/10.1186/1471-244X-12-235.

28. Said MA, Sulaiman AH, Habil MH, Das S, Bakar AKA, Yusoff RM, et al. Metabolic syndrome and cardiovascular risk among patients with schizophrenia receiving antipsychotics in Malaysia. Singap Med J. 2012;53:801-7.

29. Sahpolat M, Ari M. Higher prevalence of metabolic syndrome and related factors in patients with first-episode psychosis and schizophrenia: a crosssectional study in Turkey. Nord J Psychiatry. 2021;75(1):73-8 https://doi. org/10.1080/08039488.2020.1815080.

30. Grover S, Aggarwal M, Dutt A, Chakrabarti S, Avasthi A, Kulhara P, et al. Prevalence of metabolic syndrome in patients with schizophrenia in India. Psychiatry Res. 2012;200(2-3):1035-7 https://doi.org/10.1016/j. psychres.2012.03.043.

31. Saloojee S, Burns JK, Motala AA. Metabolic syndrome in south African patients with severe mental illness: prevalence and associated risk factors. PLoS One. 2016;11(2):e0149209 https://doi.org/10.1371/journal.pone. 0149209.

32. Owusu-Ansah A, Berko Panyin A, Obirikorang C, Agyare C, Acheampong E, Kwofie S, et al. Metabolic syndrome among schizophrenic patients: a comparative cross-sectional study in the Middle Belt of Ghana. Schizophr Res Treatment 2018:2018: 6542983. https://doi.org/10.1155/2018/65429 83.
33. Kwobah E, Koen N, Mwangi A, Atwoli L, Stein DJ. Prevalence and correlates of metabolic syndrome and its components in adults with psychotic disorders in Eldoret, Kenya. PLoS One. 2021;16(1):e0245086 https://doi. org/10.1371/journal.pone.0245086.

34. Sufa B, Abebe G, Cheneke W. Dyslipidemia and associated factors among women using hormonal contraceptives in Harar town, Eastern Ethiopia. BMC Res Notes. 2019;12(1):1-7 https://doi.org/10.1016/..metop.2021. 100108.

35. Arango C, Bobes J, Aranda P, Carmena R, Garcia-Garcia M, Rejas J, et al. A comparison of schizophrenia outpatients treated with antipsychotics with and without metabolic syndrome: findings from the CLAMORS study. Schizophr Res. 2008;104:1-12 https://doi.org/10.1016/j.schres.2008, 05.009.

36. De Hert M, van Winkel R, Van Eyck D, Hanssens L, Wampers M, Scheen A, et al. Prevalence of diabetes, metabolic syndrome and metabolic abnormalities in schizophrenia over the course of the illness: a cross-sectional study. Clin Pract Epidemiol Ment Health. 2006;2:14 https://doi.org/10. 1186/1745-0179-2-14

37. Suvisaari JM, Saarni SI, Perälä J, Suvisaari JVJ, Härkänen T, Lönnqvist J, et al. Metabolic syndrome among persons with schizophrenia and other psychotic disorders in a general population survey. J Clin Psychiatry. 2007;68(7):1045-55 https://doi.org/10.4088/jcp.v68n0711.

38. Mackin P, Watkinson HM, Young AH. Prevalence of obesity, glucose homeostasis disorders and metabolic syndrome in psychiatric patients taking typical or atypical antipsychotic drugs: a cross-sectional study. Diabetologia. 2005;48(2):215-21 https://doi.org/10.1007/s00125-004-1641-y.

39. De Hert M, Schreurs V, Sweers K, Van Eyck D, Hanssens L, Šinko S, et al. Typical and atypical antipsychotics differentially affect long-term incidence rates of the metabolic syndrome in first-episode patients with schizophrenia: a retrospective chart review. Schizophr Res. 2008;101(13):295-303 https://doi.org/10.1016/j.schres.2008.01.028.

40. Enez Darcin A, Yalcin Cavus S, Dilbaz N, Kaya H, Dogan E. Metabolic syndrome in drug-naïve and drug-free patients with schizophrenia and in their siblings. Schizophr Res. 2015;166(1-3):201-6 https://doi.org/10. 1016/..schres.2015.05.004.

41. Challa F, Gelibo T, Getahun T, Sileshi M, Geto Z, Bekele A, et al. Distribution and determinants of serum high-sensitivity C-reactive protein in Ethiopian population. Clin Chim Acta. 2021;517:99-107 https://doi.org/ 10.1016/j.cca.2021.02.013.

42. CDC. Obesity is a common, serious, and costly disease. Centers for Disease Control and Prevention 2021. https://www.cdc.gov/obesity/data/ adult.html. Accessed 13 Sept 2021.

43. Saloojee S, Burns JK, Motala AA. Very low rates of screening for metabolic syndrome among patients with severe mental illness in Durban South Africa. BMC Psychiatry. 2014;14:228 https://doi.org/10.1186/ s12888-014-0228-5.

44. Wu SH, Hui WS, Liu Z, Ho SC. Metabolic syndrome and all-cause mortality: a meta-analysis of prospective cohort studies. Eur J Epidemiol. 2010;25(6):375-84 https://doi.org/10.1007/s10654-010-9459-z.

\section{Publisher's Note}

Springer Nature remains neutral with regard to jurisdictional claims in published maps and institutional affiliations.
Ready to submit your research? Choose BMC and benefit from:

- fast, convenient online submission

- thorough peer review by experienced researchers in your field

- rapid publication on acceptance

- support for research data, including large and complex data types

- gold Open Access which fosters wider collaboration and increased citations

- maximum visibility for your research: over $100 \mathrm{M}$ website views per year

At BMC, research is always in progress.

Learn more biomedcentral.com/submissions 